\title{
CORRECTION
}

Open Access

\section{Correction to: Role of community-based active case finding in screening tuberculosis in Yunnan province of China}

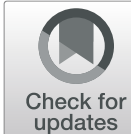

Jin-Ou Chen', Yu-Bing Qiu', Zulma Vanessa Rueda², Jing-Long Hou', Kun-Yun Lu', Liu-Ping Chen', Wei-Wei Su', Li Huang ${ }^{1}$, Fei Zhao ${ }^{3}$, Tao $\mathrm{Li}^{4}$ and Lin $\mathrm{Xu}^{1 *}$

\section{Correction to: Infect Dis Poverty \\ https://doi.org/10.1186/s40249-019-0602-0}

In the original publication of this article [1] we noticed the Fig. 4 was incorrect. The correct Fig. 4 is as below:

\section{Author details}

'Division of tuberculosis control and prevention, Yunnan Center for Disease Control and Prevention, Kunming, China. ${ }^{2}$ Universidad Pontificia Bolivariana, Medellín, Colombia. ${ }^{3}$ Clinical trail and research center of Beijing hospital, Beijing, China. ${ }^{4}$ Chinese Center for Disease Control and Prevention, Beijing, China.

Published online: 18 January 2020

\section{Reference}

1. Chen, et al. Infect Dis Poverty. 2019;8:92 https://doi.org/10.1186/540249-0190602-0.

Full list of author information is available at the end of the article 


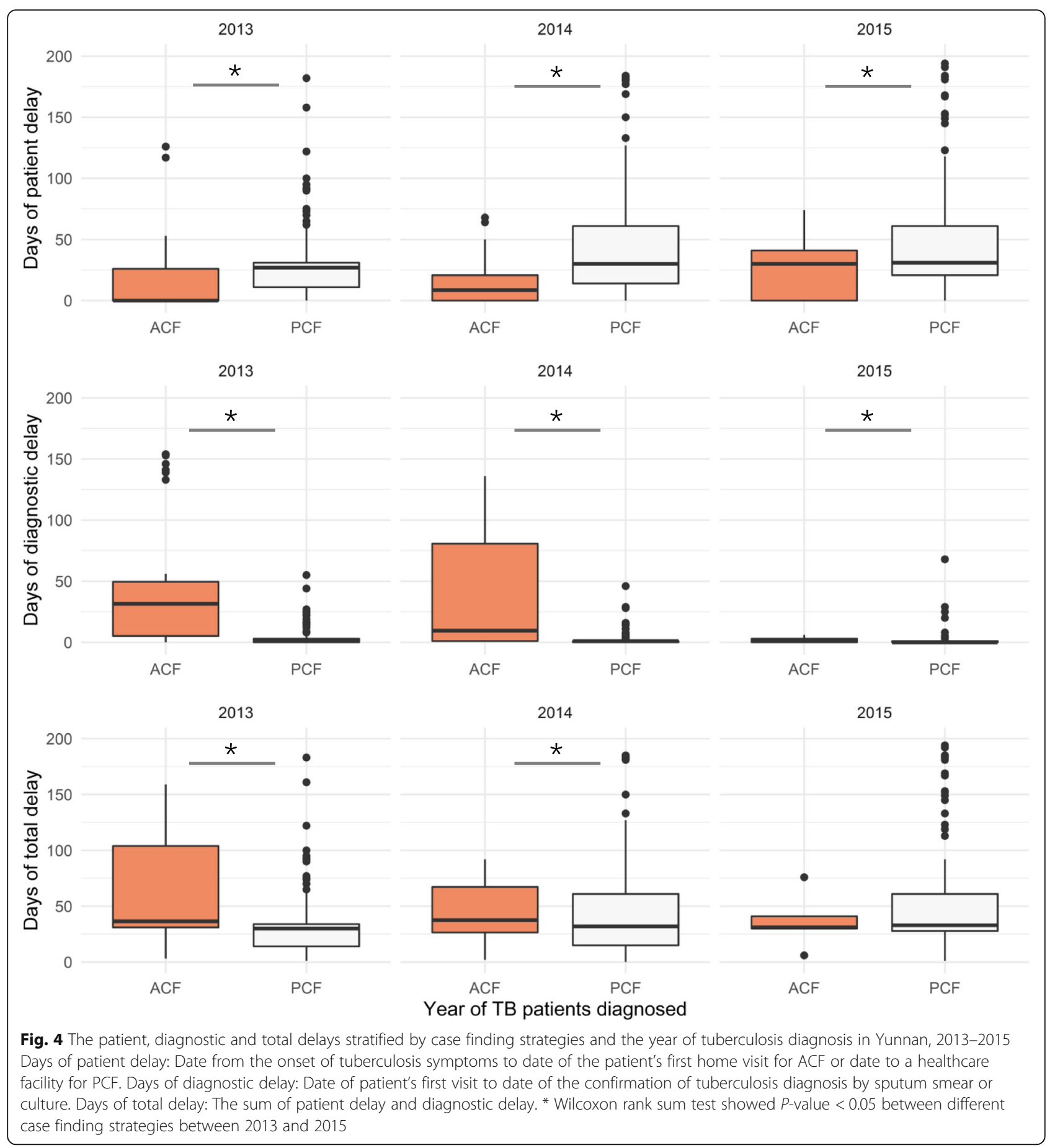

